that of the director in reference to the heredity of epileptics. Another investigation continued during the year, which involves prime utilitarian application, is that of Dr. Shull on the effects of self-fertilisation in maize, or Indian corn. His earlier conclusions, published in 1908, have been confirmed by the later studies. A striking result from the latter is that, other conditions being the same, the yield of crossfertilised plants proved 50 per cent. greater than that of the self-fertilised plants. Observational and experimental work has been carried on also along many other lines The total number of zoological individuals under study exceeded 2000, while the range of plants observed included nearly 500 species and upwards of 40,000 individuals.

Among the papers issuing from the Geophysical Laboratory is a noteworthy contribution to general physics, in which the scale of precise thermometry is extended by $1250^{\circ} \mathrm{C}$. This extension was an essential incident to the studies of mineral fusion, crystallisation, \&c., carried on in the laboratory, but it is of equal importance to other branches of physical research. Another noteworthy paper is a preliminary contribution to the long-standing question of the constitution of Portland cement. The complexity of this substance proves to be far greater than hitherto supposed, but its general characteristics have been determined, and the resources of the laboratory are adequate to complete the remaining quantitative details of the investigation. Of numerous investigations under way at the laboratory, attention may be directed to some preliminary studies of an active volcano, which indicate that the phenomena of vulcanism are within range of practicable determination, and that progress in this direction is only a question of time and adequate effort.

In the Department of Meridian Astronomy, the deductions of stellar positions and motions are proceeding expeditiously in the computing section of the department at the Dudley Observatory, so that the final catalogue, giving precise positions of all stars up to the seventh magnitude inclusive, may be expected to appear in due time. As often happens in such extensive scientific investigations, many byproducts are arising of hardly less importance than the primary ends in view. One of these, deduced from the preliminary Star Catalogue, published by the institution about two years ago, shows the mean velocities relative to the solar system of stars of different spectral types. The values derived from the "proper motions" of the catalogue are in striking agreement with those derived for the same stars by Prof. W. W. Campbell from direct measurements of the motions of these stars in the line of sight. The remarkable result which is thus brought out from independent investigations is that the speed of a star through space increases with its age.

Although the construction and equipment of the Solar Observatory are still incomplete, the members of the staff are making rapid progress with their programmes of solar, stellar, and physical observation and of computation and deduction. Thus the attainment of tangible results proceeds along with the development and installation of equipment. The observatory has now, nearly fully equipped and in use, four highly effective telescopes: the Snow, horizontal, 30-in. reflector; the two tower-telescope refractors: and the 60 -inch reflector mounted equatorially. The I50-ft. tower telescope, together with its auxiliary apparatus, constitutes the most important addition of the year in the way of equipment. Varied use of the 6o-in. equatorial proves it to be alike effective in visual, photographic, and spectroscopic work. It is especially penetrating in its capacity to reveal the characteristics of globular star clusters and spiral nebulæ.

The magnetic survey of the globe undertaken br the Department of Terrestrial Magnetism is proceeding effectively on both land and sea. Observations of the magnetic elements of declination, dip, and intensity have been made at numerous points on the continents of Asia, Africa, Australia, Europe, South America, and on the Polynesian Islands; while the non-magnetic ship Carnegie has secured a large quantity of data of immediate practical utility to navigation, and of still greater importance, doubtless, in their relations to the general problem of terrestrial physics. During the year the Carnegie traversed upwards of 23,000 nautical miles, measuring magnetic declinations at 252 different points, and dip and intensity at 172 different points at sea. In addition to this work, corresponding complete determinations were made on land at seven ports, and intercomparisons of magnetic instruments were made at thrce ports.

Unexpectedly large errors have been found almost everywhere, except in the South Atlantic Ocean, in the best compass sailing charts now in use. This is especially the case in the Indian Ocean, for which some recently issued charts are in error as much as $4^{\circ}$ to $6^{\circ}$ in the "compass variations" assigned. To meet the pressing needs of mariners for more trustworthy charts, the data obtained by the Carnegie are promptly furnished to the hydrographic establishments of the world engaged in the publication of magnetic charts. It appears from the investigations of the department that the chief source of the errors in existing charts lies in a lack of knowledge of the secular variation of the magnetic elements. It is worthy of note, also, in this connection, that observations of atmospheric electricity and atmospheric refraction have been carried on during this voyage of the Carnegie. The importance of precise navigation in recent times gives special interest to the outstanding uncertainties due to atmospheric refraction.

\section{THE ROAD: PAST, PRESENT AND FUTURE.}

The Present.

A GRET improvement took place when Macadam and Telford brought the results of their study and their inventive powers to bear, giving a road well laid below and a crust of small angular stones, which when pressed down close produced an infinitely better road than had been known before. But it must be admitted that while they provided better materials for a good highway, their mode of completing it entailed upon the road user and his horse and vehicle a great deal of unpleasant roadmaking work, involving much temporary discomfort and much wear and tear to animal and carriage. The road user had to apply his vehicle to roller work, to force the stones into a closely packed surface. When completed it was a good road for the traffic of the day, but oh! it was trying work when the road user's vehicle not only conveyed his passengers or his goods, but was compelled to act the part of a road roller.

A great change took place when the heavy steam roller was introduced, which in one operation pushed the stones down into position. It afforded a blessed relief to those who used the roads with horses. But though advantageous in saving the road user and

1 From a discourse delivered at the Royal Institution on Friday, February 16 , by the Right Hon. Sir John H. A. Macdonald, K.C.B., F.R.S. Exigencies of space prevent what was said on the Past being given.-F.D.

NO. 2214 , VOL. 89] 
his horse and carriage, and more expeditiously completing the new surtace, it was not possible to provide a closely fitted road, which should have its interstices filled up by the chip and grit from the stones themselves, and which was an essential desideratum according to the Macadam theory. His principle was that no water should enter the surface of the road or penetrate beneath the crust. To keep water out of the road was one of the most essential points, if it was to be efficient. He strongly condemned any insertion of loose material into the interstices of the metal, or allowing water to enter between the stones of the crust. These maxims of Macadam came to be disregarded when steam rolling was introduced. When rolling was to be done in one operation, a device had to be resorted to, that the spaces between the stones might be closed by added packing, and this has been done by making what can only be described as a soup of dirt and water and pouring it upon the stones and brushing and rolling this liquid mud into the crust of the road. The road thus when opened for use is crusted with a coating of stones, the only binding of which is water thickened with dirt, or perhaps dirt diluted with water is the proper description. The result is that it can never be a good road in wet weather, and can never be a good road in dry weather. As long as it is in a slightly damp state, and not subjected to severe wet weather or longcontinued drought, it may be a fairly good road. In wet weather water can get in where it has come out, reproducing the mud soup, and the traffic squeezes it up and out of the road. In dry weather, the binding being reduced in bulk and loosened by the evaporation of the moisture which gave the inserted dirt some cohesion, the stones move and are picked out of the surface, and so holes are left for the water to lodge in the dirt below when again rain begins to fall. What would Macadam say, if he could visit the scene of his scientific labours, to hear the phrase "water binding" used to describe the means employed for consolidating the crust. To call a water-formed road a macadamised road is a contradiction in terms. His emphatic declaration was: "Every road is to be made of broken stones, without mixture of earth, clay, chalk, or any other matter that will imbibe water."

But further, the road roller has not in another aspect proved to be an unmixed blessing. For it is not uncommon to see that its use has developed another evil. The heavy road roller coming on to a layer of stones, surrounded with liquid and therefore non-resisting mud, and pressing down the stones by its weight, necessarily must move the water and the dirt in suspension, otherwise the stones would not go close together. The liquid is therefore squeezed out of the way, and as the great width of the roller prevents its escape sideways, except at the edges, it must go forwards, and (water being practically incompressible) forces the water and the dirt and the stones in front upwards, forming a ridge in front. The roller advances, and when it cannot force the ridge farther forward, it then mounts it and descends in front, and so $d a c a p o$, with the consequence that the road becomes a series of ridges and furrows, and when drying up resembles a mackerel's side, a series of dark-toned wet hollows and light-toned dry mounds. No worse state of matters for the traveller and his vehicle, or for durability of the road surface, can be conceived.

\section{The Future.}

What is the road of the future to be? It is a question which all who are associated with the management of roads have come to see calls imperatively for an answer. The problem is to find the NO. 2214 , VOL. 89] best mode by which a road can be constructed, which will not have its surface broken by. traftic, and will make transit easier both for passengers and goods, and shall neither form puddle holes nor exude mud to clog the vehicles and to form thick dust when the weather is dry; in short, that there shall be no loose material from the road, except the small quantity caused by surface wear, which it is found is but trifling when a sound crust has been rolled in. That such a road can be laid anyone may see by paying a visit to the Thames Embankment, the traffic on which was small formerly, the road being shunned as one of the worst in the country, but which is now used by an enormous number of vehicles, often as many as 1600 in an hour. It will be seen there that water on the surface dries off very quickly, there being no mass of mud to hold it, and that in the driest weather there is practically no dust. No watering is done during the day, the surface receiving one washing during the night, because of the horse traffic. But there is no need for the use of water carts by day. Even during the long drought of Igrr there was no watering, yet there was no appreciable dust.

The necessity for the development of road improvement as a matter of national concern is now recognised, and this has led to the establishment of the Road Board, as a Government department, to the charge of which the money raised by taxation of motor vehicles and motor fuel is handed over to be administered in aid of road improvement.

The Board encourages road improvement by giving grants in aid to those road authorities who undertake worlss of improvement in their districts. The Board has also been conducting, and will continue to conduct through their engineer and technical advisers, experiments, both in the laboratory and on the road itself.

I shall conclude by directing your attention to some of the results of recent experiments, by which I think you will see that it has been possible for the Board with the aid of its staff, and the experience of numerous surveyors who have been experimenting for many years, to obtain valuable and practical information, as regards the choice of material, its manipulation, its proportions, and the mode of laying it, which may ensure that good roads can be made, roads which will keep their surface sound for twice as long as the water-bound macadam road, and will not become uneven and breals into holes, which was the fate of all the roads of the past.

The question: "What shall be the weight-bearing crust?" is one of vast importance, and this is engaging the attention of the advisers to the Road Board. I do not intend to dogmatise on the subject, but only to show you what steps of progress are being made, what has already been consummated in the production of róads which are to the old water-bound macadam what the genuine macadam was to the old track of foot-deep mud and bulky stones. One thing is now universally recognised, that the road of the future shall be a truly bound road, in which, whatever kind of stone is used-a matter into which there is not time to enter-that stone shall be held together bv some pitchy or bituminous material, so that it shall be indeed a crust and not something which has no real cohesion, and into which Macadam's enemy, the water, can make its way whenever water falls. That this result has been attained in a practical way is manifest from the pieces of road crust cut out after thev have been under traffic for long periods.

Roads formed as regards the crust in this way are now common. Many can be seen in Kent and other counties near London, and stretches are being laid throughout the kingdom. Great success was attained 
by many surveyors, and notably at an early date by Mr. Hooley, of Nottingham, in putting together road crusts with the aid of tarry components substituted for mud binding.

I have probably said enough to show that a good road, which shall keep smooth, be impervious to water, and not tend to disintegrate, is now an accomplished fact, and I only need to add that the cost, taken over a series of years, will not be more-indeed there is good ground to believe it will be less-than that of a road as it has been constructed in the past.

One question remains-will it not be well to endeavour to provide an elastic skin or carpet to lie between the vehicle and the bearing crust? The laboratory experiments made seem to indicate that this will be accomplished. Research has been made with pitch and with bitumen, and the conclusion has been reached that pitch will not give satisfactory results, but bitumen will do so. A stick of pitchy material has very little resiliency when subjected to strain. A bitumen stick of the same size is capable of being twisted without fracture, and when freed slowly resumes its shape.

It is expected that with such material laid on the top of the main road crust and integrated with it a valuable road protection will be supplied, so that the road crust will be practically permanent, the upper protecting sheet being remade up and relaid as required.

For the carpet or topping, the case is somewhat different from the crust. Here strength is not of so much importance as the elastic and silencing qualities, and the freedom from liability to produce any dust in summer or mud in winter. Another requirement which is very difficult to meet in this transition age is that of giving a surface good for motor and mechanical transport, and which will not be slippery, and will afford good foothold for horses. The carpet must be a compromise; it must not be as hard as motorists would wish for, but just so hard that it will wear a little and yet be cheap and easy to maintain.

\section{UNIVERSITY AND EDUCATIONAL INTELLIGENCE.}

Science announces that the Massachusetts Institute of Technology has received from a donor whose name for the present is anonymous a gift of $500,000 l$. for the erection of the buildings on its new site.

Since our last issue, Lord Haldane, chairman of the Royal Commission on University Education in London, has received a promise of $50,000 l$. towards the purchase of the site on the Duke of Bedford's estate north of the British Museum for London University. This brings the total amount subscribed for a new site and Senate house for the University to $355,000 l$.

THE new buildings of the Spinning Section of the Textile Department of the University of Leeds will be opened by the Master of the Clothworkers' Company on Friday, April 26. The ceremony, at which the chancellor of the University (the Duke of Devonshire) will be present, will take place in the hall of the University. The Clothworkers' Company, whose liberality has made the new extension possible, will be represented by the Master (Mr. F. G. Fitch), the Warden (Mr. G. H. Nussey), Mr. A. W. Snow, Sir Owen Roberts, Sir Swire Smith, Mr. William Latham, K.C., and the Right Hon. G. W. Balfour.

A PRIZE fellowship of $120 l$. was offered by the Federation of University Women in December last, open to women who have been engaged during a number of years in research, the results of which NO. 2214 , VOL. 89$]$ have been published. Thirteen applications were received, investigations in zoology, geology, physiology, botany, physics, history, Oriental religions, English literature, French literature, and philosophy being submitted. 'The fellowship has been awarded to Miss C. E. Spurgeon, docteur de 1'Université de Paris, lecturer in English literature at Bedford College, London. Miss Spurgeon's published work deals chiefly with mysticism in poetry and with Chaucer criticism.

THE annual report on the work and progress of University College, London, has just been issued. The total number of students during the session I910-II was I600; of this number there were in the faculty of science 197 undergraduate and non-matriculated students, and 90 postgraduate and research students. The report contains a résumé of the chief activities of the year, together with appendices showing the list of original papers and other publications recording the results of investigations carried on in the college. There is also a summary of the important developments of the year. Among these, the two most noteworthy are to be found in the progress made in the scheme for new chemical laboratories, due especially to the gift by Sir Ralph C. Forster of $30,000 l$. towards the buildings, and in the anonymous benefaction of $30,000 \mathrm{l}$. primarily for the building of the new School of Architecture. The report shows that a sum of about $10,000 l$. is still required to complete the new chemical laboratories.

$I_{N}$ an address at Boston on March 6, Dr. R. C. Maclaurin, president of the Massachusetts Institute of Technology, said nearly everyone recognises today the power and might of science, and nearly everyone pays it at least the homage of the lips. He reviewed some of the controversies that marked the foundation of the Massachusetts Institute of Technology. It was attacked only a half-century ago on the ground that science is antagonistic to humanity. The idea was that science was unsuited to be an instrument of education because it dealt with nature rather than with men. This limited idea can find little favour to-day, when science is seen to be human to the core. Even when it deals with nature it deals with man's views of nature; but, apart from this, half a century of its sway has displayed to the world something of the immensity of its power to make for human betterment. "Science in the service of man," continued Dr. Maclaurin, "is indeed the watchword of modern progress, and men and women who could serve their fellows in the future will find themselves handicapped unless they have learned to serve with the method and in the spirit of science."

THE recently published report of the Board of Education for the year I910-I I (Cd. 6II6) gives much useful information concerning the number of efficient secondary schools in England and of pupils in them. The total number of schools regarded as eligible for grant during I910-11 was 862 , as compared with 841 during I909-io. In these schools there were, on January $3 \mathrm{I}$, roiI, 79,506 boys and 66,378 girls, as compared with 76,699 boys and $64,45^{\circ}$ girls in 19io. There were 96 other schools recognised by the Board as efficient during I9IO-II, though they were not on the grant list. In these schools on the date given above there were 9946 boys and 7666 girls. So far as the number of pupils in public elementary schools is concerned, the report shows that in I9I0-II the number under five continued to fall, as in previous years, and, in addition, during this year there was a decrease of $\mathrm{S}_{11} 8$ in the number of pupils over twelve; 